\title{
INNATE IMMUNITY AND INFLAMMATION IN SYSTEMIC SCLEROSIS
}

Robert Lafyatis ${ }^{*}$ and Michael York

Rheumatology Section, Boston University School of Medicine, Boston, MA

\section{Abstract}

Purpose of review-Recent advances in our understanding of innate immunity and inflammation have direct bearing on how we understand autoimmunity, fibrosis and how innate immune sensors might stimulate both of these key features of systemic sclerosis (SSc)

Recent findings-Nucleic acid containing immune complex (IC) activation of toll-like receptors (TLRs) and induce expression of interferon responsive genes (IRGs) and autoantibodies in systemic lupus erythematosus (SLE). Recent studies indicate that increased SSc expression of IRGs may also be mediated by nucleic acid containing ICs. An expanding array of Non-TLR innate immune pathways have recently been discovered. In particular, nalp3 mediated inflammasome activation of caspase- 1 and conversion of pro-IL-1 to IL-1 play a key role in silica- and bleomycin-mediated pulmonary fibrosis. TLR activation stimulates other inflammatory mediators, such as IL-1, IL-6 and TNFa in macrophages and dendritic cells. Activation of these and other inflammatory mediators, through TLR and non-TLR sensors, may cooperate to upregulate fibrotic mediators such as TGF $\beta$ and IL-13.

Summary-These observations provide a new paradigm for understanding the relationship between immunity/inflammation and fibrosis. New therapeutics, including TLR agonists and antagonists, and IFN inhibitors are currently under investigation. Further understandings of inflammasome mediated fibrosis may provide further insights into SSc pathogenesis.

\section{Keywords}

Scleroderma; toll-like receptors; inflammasome; interferon

\section{INTRODUCTION}

The complex clinical and pathological features of systemic sclerosis (SSc) complicate understanding the role of the immune system in pathogenesis. Circulating autoantibodies, altered immune mediators and infiltration of mononuclear cells in affected organs argue that immune system dysfunction drives pathogenesis. The clinical overlap with other more clearly defined autoimmune diseases, particularly systemic lupus erythematosus (SLE), further supports immune system activation in the disease process. However, unlike SLE, autoantibodies are not deposited in tissues in SSc and have not been directly implicated in pathology. Thus, the role of autoantibodies and cellular immune system activation in SSc

\footnotetext{
*Address correspondence to: Robert Lafyatis Boston University School of Medicine 88 E Concord St Boston, MA 02118 Telephone\# 617638-4312 Fax\#: 617 638-5226 lafyatis@bu.edu.

This is a PDF file of an unedited manuscript that has been accepted for publication. As a service to our customers we are providing this early version of the manuscript. The manuscript will undergo copyediting, typesetting, and review of the resulting proof before it is published in its final citable form. Please note that during the production process errors may be discovered which could affect the content, and all legal disclaimers that apply to the journal pertain.
} 
appears to be different though related to alterations seen in SLE. Increasingly, innate immune disturbances have become a focus in autoimmune illnesses, as it became clear that such disturbances could precipitate autoantibody production and autoimmune disease. The association of certain chemical exposures with scleroderma-like illnesses further supports the notion that non-antigen specific innate immune responses to inflammatory stimuli might cause SSc.

\section{TOLL-LIKE RECEPTORS AND INNATE IMMUNTIY IN SSC}

Recent understandings highlight how "first-line" innate immune defenses can promote autoimmunity. In normal, early immune responses against infectious agents, immune cells recognize microbes through pattern recognition receptors (PRPs) (1).

\section{Toll-like receptors in autoimmune disease}

PRPs, most prominently toll-like receptors (TLRs), control immune responses by detecting common molecular motifs, including RNA ligands by TLR3, TLR7 and TLR8, DNA ligands by TLR9 and bacterial cell surface proteins such as lipopolysaccharide (LPS) or endotoxin that is a ligand for TLR4 (See Table I). Activation of these or other TLRs on dendritic cells, monocyte/macrophages and B cells stimulate inflammatory cytokines, antigen presentation and development of the adaptive immune response. Mammalian DNA and RNA do not normally engage these receptors, in part because they recognize structural motifs found more commonly on bacterial DNA such as CpG motifs, but also because these receptors are sequestered inside the cell in an endosomal compartment that normally excludes endogenous nucleic acids.

Increasingly, data from both murine and human studies have implicated TLR activation in the pathogenesis of SLE (2). SLE patient sera contain endogenous ligands for TLRs, particularly the nucleic acid sensing TLRs, TLR7, TLR8 and TLR9 (3). The ligands for these receptors in SLE sera are immune complexes (ICs) formed by autoantibodies to nucleic acids or nucleic acid binding proteins. Autoantibodies in such ICs bind nucleic acid directly (anti-DNA antibodies), or indirectly by binding to nucleic acid binding proteins, such as Sm proteins. Dendritic and B cells can internalize these nucleic acid-containing ICs through Fc and surface immunoglobulin receptors, respectively (4-7). Such internalization targets the bound nucleic acid to the proper endosomal compartment, activating TLR7 (by RNA) or TLR9 (by DNA). TLR activation leads to dendritic cell production of interferon (IFN) and B cell maturation. These observations provide new pathogenic functions for anti-nuclear autoantibodies in SLE, discussed further below in the context of SSc, and indicate that innate immunity regulates key aspects of autoimmunity.

Although the role of TLRs or other PRPs in SSc is less clear, several parallels can be drawn that suggest mechanisms of innate immune dysfunction operating in SLE may also be important in SSc. In particular, both diseases are associated with autoantibodies to nucleic acid-binding proteins and both diseases are associated with increased expression of interferon-responsive genes by peripheral blood mononuclear cells.

\section{Interferon-responsive genes and innate immunity in SSc}

Several years ago we and others showed that SSc patients, like SLE patients, show increased expression of interferon-responsive genes (IRGs), known as the interferon "signature" $(8,9)$. IFNs include type I, type II and more recently identified type III IFNs. The type-I IFNs include 13 , mostly co-regulated, IFN $\alpha$ subtypes and IFN $\beta$, signaling through a common receptor. Although these IFNs are difficult to measure directly in the blood, serum IFN $\alpha$ can be detected through biological assay in SLE patients, where it correlates with the IFN signature (10). 
Dendritic cells, particularly plasmacytoid dendritic cells (pDCs), are the major source of IFNa and these cells secrete high amounts of IFN upon TLR 7 or TLR9 activation.

In contrast to SLE, the IFN responsible for stimulating IRGs in SSc is not known. As the type I IFNs, IFNa and IFNb, stimulate the same receptor, and type I and type II IFNs stimulate a similar set of genes, it is not possible to tell clearly from the pattern of PBMC gene expression which IFN is responsible for the IFN signature in SSc patients. If similar mechanisms as those in SLE stimulate the IFN signature in SSc patients, then we would anticipate primarily IFN $\alpha$. This would implicate dendritic cells, the major source of IFN $\alpha$. On the other hand, non-immune cells including fibroblasts produce IFN $\beta$, and TH1 and NK cells are the primary sources of IFN $\gamma$. Thus, determining the type(s) of IFN driving IFN gene expression in SSc will also provide insight into the cell types activated in the immune response.

Sera or purified Immunoglobulin from SSc patients can stimulate IFN $\alpha$ by peripheral blood mononuclear cells (PBMCs) (11). This activity is mainly found in sera containing autoantibodies to topisomerase. IFN $\alpha$ secretion stimulated by SSc sera was blocked by the addition of an antibody to BCDA2, a receptor that inhibits IFN $\alpha$ production by pDCs. Activity was also blocked by antibody to Fc $\gamma$ RII, the surface receptor that has been shown to be important for IC uptake, and bafilomycin, an inhibitor of endosomal acidification. Together these results are most consistent with the notion that ICs in SSc stimulate endosomal TLRs after Fc-mediated internalization by pDCs, i.e., the same mechanisms implicated in SLE (5).

Type I IFNs have been implicated in B cell maturation $(12,13)$, but have not generally been considered pathogenic factors in SSc. IFNs block the effects of TGF $\beta$ on fibrosis, suggesting that they might actually ameliorate this aspect of SSc pathogenesis. However, TLR activation of dendritic cells and macrophages also stimulates IL-1, TNF and IL-6 production, and these or other undefined mediators might drive inflammation and fibrosis in SSc.

\section{Anti-nuclear autoantibodies in SSc}

Autoantibodies found in SSc patients are mostly distinct from those seen in SLE. However, many of the proteins targeted by SSc-associated autoantibodies, strikingly, share the common feature of binding, directly or indirectly, to nucleic acids. Although topoisomerase-I is known as a DNA-nicking enzyme, it also associates with a variety of proteins that bind RNA (14). Thus, ICs in SSc sera containing anti-topoisomerase antibodies might bind DNA or RNA. As RNAse blocks innate immune activation by topoisomerase-containing ICs more efficiently than DNAase (11), TLR7/8, the single stranded RNA sensors, are most strongly implicated in topoisomerase-1 associated innate immune activation. However, this study did not exclude the possibility that other autoantibodies present in the sera were responsible for the observed activity.

Anti-centromere autoantibodes target a variety of centromere proteins, but most consistently CENP-B (15). CENP-B binds to highly repetitive a-satellite DNA through a highly conserved 17 base pair sequence known as the CENP-B box (16). Thus, ICs formed from autoantibodies binding centromere proteins might be associated with $\alpha$-satellite DNA. One might anticipate that such ICs could have similar effects on innate immune activation as anti-DNA antibodies in SLE, although the specific sequences associated with centromere DNA could potentially lead to different immune responses, as has been seen for responses to synthetic DNA sequences (17).

Anti-nucleolar antibodies are seen in $~ 30 \%$ of SSc patients and a smaller proportion of SLE patients. These antibodies target a subclass of small nucleolar ribonuclear proteins (snoRNPs) that methylate rRNA, including U3 snoRNP and associated proteins: fibrillarin and Mpp10 (18). Fibrillarin, the most common target of anti-nucleolar antibodies, binds directly to 
snoRNAs through the C/D box, two highly conserved sequences found in both the 3' and 5' ends of C/D snoRNAs $(19,20)$. Thus, antibodies to fibrillarin might deliver C/D snoRNA associated with fibrillarin to TLR7/8 receptors. As for DNA activation of TLR9, the sequence of RNA affects TLR7/8 activation (21). Thus, RNA sequences specific for snoRNAs may affect innate immune responses. In particular, RNA sequence can affect the degree of IFNa, IL-6 and TNFa production. One might speculate that TLR7 activation by RNA in anti-Sm ICs found in SLE patients might elicit different responses from RNA in anti-nucleolar antibody ICs, but there is currently no data to directly support this possibility.

\section{TLR activation of autoreactive B cells}

In addition to stimulating dendritic cells, TLR activation can be a key step in the maturation of autoreactive B cells. Anti-chromatin antibodies found commonly in SLE patients can stimulate B cell proliferation that depends on uptake of the IC through surface immunoglobulin and subsequent interaction of DNA in the IC with TLR9 (7). Autoantibodies to RNA binding proteins can in the same manner stimulate TLR7-mediated B cells proliferation (4). Anti-Sm autoantibodies markedly stimulate B cell proliferation in the presence of purified snRNPs. This stimulation depends on RNA in the snRNP IC, and requires Myd88, a principal signaling component for most of the TLRs, including TLR7. These data suggest that ICs or simply circulating cell debris containing centromere DNA and/or snoRNPs might bind directly to B cells expressing surface autoantibody specific for, respectively, CENP-B or fibrillarin. Internalization of the DNA or RNA containing material might activate, respectively, TLR9 or TLR7 and expansion of autoantibody producing B cells.

Notably in relationship to SSc-associated autoantibodies, TLR7 has been strongly implicated in formation of anti-nucleolar antibodies in mice harboring the Y-linked autoimmune accelerator (Yaa) gene. Mice harboring a deletion of the inhibitory Fc $\gamma$ RIIb receptor spontaneously develop autoimmune disease and antinuclear autoantibodies. In Fc $\gamma$ RIIb deficient mice, the Yaa gene accelerates disease severity, but also shifts the autoantibody profile toward anti-nucleolar antibodies. Recent studies have shown that the Yaa includes a duplication of TLR7 (22). These results emphasize a strong dosage effect of TLR7 on autoantibody production and suggest that TLR7 mediates activation of autoreactive B cells that have taken up nucleolar/RNA-containing cellular debris through surface immunoglobulin receptors.

\section{Linking TLRs to fibrosis}

How TLR stimulation leads to fibrosis is not certain, but in most cases is likely mediated by TGF $\beta$ (23). In addition, recent studies have suggested that TLR activation might directly stimulate fibroblast conversion to profibrotic myofibroblasts through TLR3 (24) or TLR9 (25. Sera from SSc patients, but not healthy controls or patients with primary Raynaud's phenomenon, show evidence of a circulating TLR4 agonist \{ van Lieshout, 2009 \#588). The nature of this putative TLR4 ligand remains unclear. However, other studies of anti-fibroblast antibodies (AFA) have also implicated TLR4 agonist activity in SSc serum. AFA-induced expression of CCL2 by fibroblasts is diminished in TLR4-deleted fibroblasts (26). These latter studies are similar to studies suggesting that SSc sera contain TLR7 agonist activity discussed above (11). Further studies should clarify the composition and TLR specificity of these activities.

\section{Matrix derived TLR ligands}

Several TLR ligands are generated from matrix molecules during tissue injury. Hyaluronan generated during acute lung injury can activate TLR2 and TLR4, contributing to macrophage activation (27). Biglycan, a small leucine-rich proteoglycan, can also act as a TLR2 or TLR4 ligand (28) and the extra domain A (EDA), found in one of the alternatively spliced forms of 
fibronectin, is a ligand of TLR4. Stimulation of TLRs by these matrix molecules provides another source for innate immune activation during inflammation and might act to initiate or perpetuate inflammation and fibrosis in SSc.

\section{TLR-INDEPENDENT INNATE IMMUNITY AND FIBROSIS}

Although TLRs link adaptive to immune responses and are required for appropriate immune sensing they do not account for all adjuvant-like innate immune activation (29). TLRindependent innate immune sensors include mediators in the NOD-like receptor (NLR) family. NLRs include NOD1 and NOD2 that recognize bacterial peptidoglycan fragments (30), inducing NF-kB, and cryopyrin/Nalp3 that recognizes a wide array of ligands and induces the inflammasome (see Table II). Other innate immune sensors are the helicases: retinoid acidinducible gene I (RIG-I) and melanoma differentiation-associated gene-5 (mda5). These receptors sense cytoplasmic double stranded RNA with binding and downstream activation of IFN $\beta$, thus sharing these features with TLR3, an endosomal dsRNA sensor $(31,32)$. Recently, another innate immune receptor for cytosolic DNA, AIM2, has been described that activates caspase-1/inflammasome (33).

\section{Silica, bleomycin and the inflammasome}

Environmental or occupational exposure to silica dust leads to fibrosis (34) and has been associated with SSc (35). Recently, several groups have shown in murine models that silica dust activates inflammation and fibrosis through the inflammasome (36,37). Activation of the inflammasome also contributes to bleomycin-induced lung injury (38). The inflammasome is an intracellular protein complex that includes cryopyrin/Nalp3, originally identified by gainof-function mutations causing the autoinflammatory diseases, Muckle-Wells syndrome, familial cold autoinflammatory syndrome, and neonatal-onset multisystem inflammatory disease (39). It is triggered by "danger signals", including monosodium urate and calcium pyrophosphate dihydrate crystals. Nalp3 activates caspase-1 converting the inflammatory cytokines, pro-IL-1 $\beta$, pro-IL-18 and pro-IL-33 into their active forms. Interleukin-1 plays a key role in both lung fibrosis stimulated by both silica and bleomycin. The mechanism linking IL-1 to fibrosis is uncertain, but involves TGFb/smad3 dependant stimulation (40). Bleomycin induced pulmonary fibrosis also depends on TLR signals and has recently been described as a TLR2 ligand (41). Inflammasome- and TLR-mediated signals provide complementary activities with TLR agonists stimulating pro-IL-1 production and caspase-1 converting it to its active form (39). Despite these links to fibrosis, a role for the inflammasome has not been shown in SSc.

\section{Toxic oil syndrome and innate immunity}

The 1980's outbreak of "toxic oil syndrome" (TOS) in Spain following ingestion of contaminated rapeseed oil that had been intended for industrial use caused pulmonary hypertension a scleroderma-like illness with autoantibody production and skin thickening. Although, the contaminant leading to disease was not definitively established, two molecules have been identified as probable culprits: 1,2-di-oleyl ester (DEPAP) and oleic anilide (42, 43). Evidence for a role of the innate immune system is supported by increased secretion of IL-1 and IL-6, and activation of NF-kB in mice treated with oleic anilide (44), and development of high titer anti-nuclear antibodies in genetically predisposed MRL/lpr mice exposed to these oils (45). Although such activity has not been directly related to innate immune activation, fatty acid esters have known adjuvant activity (46).

\section{Gadolinium and macrophage activation}

Gadolinium exposure leading to nephrogenic systemic fibrosis appears to be mediated by macrophage activation of profibrotic cytokine secretion (47). The receptor for this is unknown 
but gadolinium is known to block a variety of ion receptors and activate the vallinoid receptor (48).

\section{MONCYTE/MACROPHAGES AND IL-13 IN SSc AND FIBROSIS}

Macrophages are a prominent cell type in the dermis of scleroderma patients (49) and become profibrotic through alternative activation by IL-13.

\section{Monocyte/macrophage activation in fibrosis}

Both circulating mononcytes and tissue macrophages in SSc patients highly express Siglec-1/ sialoadhesin, a marker type-I IFN (9). Subsequent studies have found that monocyte Siglec-1 expression correlates with disease severity in SLE, but whether this marker of IFN-induced macrophage activation is associated with disease severity or progression in $\mathrm{SSc}$ has not been reported. Dermal macrophages in SSc patients also show increased expression of the IFN $\gamma$ inducible gene, allograft inflammatory factor-1 (AIF1) (50,51). Although upregulation of these genes implicates different IFNs, it is important to recognize that type I and type II IFNs stimulate similar sets of genes and both SIglec-1 and AIF1 might be stimulated by either type I or type II IFN (IFN $\gamma$ ). Macrophages can secrete a variety of profibrotic mediators, including PDGF and TGF $\beta$. A paradigm for macrophage activation has been defined on the basis of cytokines released by the two Th subtypes (52). "Classically activated" monocytes are activated by the Th1 cytokine IFNg, whereas alternatively activated macrophages are activated by Th2 cytokines IL4 and IL13 (52). Alternatively activated macrophages are proposed to be profibrotic, possibly by activating TGFb. This paradigm has not been fully explored yet in SSc.

\section{IL-13 and fibrosis}

Bleomycin-induced skin fibrosis is partially dependent on skewing toward TH2 cytokines particularly IL-13, as more severe fibrosis is seen in mice deleted of the TH1-skewing transcription factor, t-bet $(53,54)$. Despite these studies suggesting that $\mathrm{T}$ cells are important in bleomycin-indcued fibrosis, dermal fibrosis can also be induced by bleomycin in nude and rag mice $(53,55)$ and lung fibrosis by bleomycin can be induced in scid mice $(56)$. Thus, $\mathrm{T}$ cells are not required for bleomycin to induce fibrosis, suggesting that monocyte/macrophages or dendritic cells may be the key cells producing IL-13. Lung alveolar macrophages from patients with pulmonary fibrosis have been shown to produce IL-13 (57), consistent with the notion that this profibrotic cytokine may be a key mediator of innate immune induced fibrosis. IL-13 is elevated in the serum of SS patients, suggesting that it plays a role in fibrotic disease in SSc (58).

\section{CONCLUSIONS}

Multiple independent studies show that innate immune sensors can lead to autoantibody production and fibrosis. The common feature of autoantigens in SSc and SLE patients as nucleic acid-binding proteins implicates nucleic acid sensing TLRs, TLR7, TLR8 and TLR9 in pathogenesis. Matrix molecules and circulating innate immune activators in SSc patients suggest possible roles for TLR2 and TLR4. Environmentally induced scleroderma-like illnesses highlight the potential importance of inflammasome activation and IL-1 in SSc pathogenesis

\section{REFERENCES}

1. Akira S, Uematsu S, Takeuchi O. Pathogen recognition and innate immunity. Cell 2006;124(4):783801. [PubMed: 16497588]

2. Lafyatis R, Marshak-Rothstein A. Toll-like receptors and innate immune responses in systemic lupus erythematosus. Arthritis Res Ther 2007;9(6):222. [PubMed: 18086320] 
3. Marshak-Rothstein A. Toll-like receptors in systemic autoimmune disease. Nat Rev Immunol 2006;6 (11):823-35. [PubMed: 17063184]

4. Lau CM, Broughton C, Tabor AS, Akira S, Flavell RA, Mamula MJ, et al. RNA-associated autoantigens activate B cells by combined B cell antigen receptor/Toll-like receptor 7 engagement. J Exp Med 2005;202(9):1171-7. [PubMed: 16260486]

5. Means TK, Latz E, Hayashi F, Murali MR, Golenbock DT, Luster AD. Human lupus autoantibodyDNA complexes activate DCs through cooperation of CD32 and TLR9. J Clin Invest 2005;115(2): 407-17. [PubMed: 15668740]

6. Boule MW, Broughton C, Mackay F, Akira S, Marshak-Rothstein A, Rifkin IR. Toll-like receptor 9dependent and -independent dendritic cell activation by chromatin-immunoglobulin G complexes. J Exp Med 2004;199(12):1631-40. [PubMed: 15197227]

7. Leadbetter EA, Rifkin IR, Hohlbaum AM, Beaudette BC, Shlomchik MJ, Marshak-Rothstein A. Chromatin-IgG complexes activate B cells by dual engagement of IgM and Toll-like receptors. Nature 2002;416(6881):603-7. [PubMed: 11948342]

8. Tan FK, Zhou X, Mayes MD, Gourh P, Guo X, Marcum C, et al. Signatures of differentially regulated interferon gene expression and vasculotrophism in the peripheral blood cells of systemic sclerosis patients. Rheumatology (Oxford) 2006;45(6):694-702. [PubMed: 16418202]

9. York MR, Nagai T, Mangini AJ, Lemaire R, van Seventer JM, Lafyatis R. A macrophage marker, Siglec-1, is increased on circulating monocytes in patients with systemic sclerosis and induced by type I interferons and toll-like receptor agonists. Arthritis Rheum 2007;56(3):1010-20. [PubMed: 17328080]

10. Hua J, Kirou K, Lee C, Crow MK. Functional assay of type I interferon in systemic lupus erythematosus plasma and association with anti-RNA binding protein autoantibodies. Arthritis Rheum 2006;54(6):1906-16. [PubMed: 16736505]

**11. Kim D, Peck A, Santer D, Patole P, Schwartz SM, Molitor JA, et al. Induction of interferon-alpha by scleroderma sera containing autoantibodies to topoisomerase I: association of higher interferonalpha activity with lung fibrosis. Arthritis Rheum 2008;58(7):2163-73. [PubMed: 18576347]

12. Banchereau J, Pascual V. Type I interferon in systemic lupus erythematosus and other autoimmune diseases. Immunity 2006;25(3):383-92. [PubMed: 16979570]

13. Ronnblom L, Eloranta ML, Alm GV. The type I interferon system in systemic lupus erythematosus. Arthritis Rheum 2006;54(2):408-20. [PubMed: 16447217]

14. Czubaty A, Girstun A, Kowalska-Loth B, Trzcinska AM, Purta E, Winczura A, et al. Proteomic analysis of complexes formed by human topoisomerase I. Biochim Biophys Acta 2005;1749(1):13341. [PubMed: 15848144]

15. Earnshaw WC, Rothfield N. Identification of a family of human centromere proteins using autoimmune sera from patients with scleroderma. Chromosoma 1985;91(3-4):313-21. [PubMed: 2579778]

16. Muro Y, Masumoto H, Yoda K, Nozaki N, Ohashi M, Okazaki T. Centromere protein B assembles human centromeric alpha-satellite DNA at the 17-bp sequence, CENP-B box. J Cell Biol 1992;116 (3):585-96. [PubMed: 1730770]

17. Krieg AM. Development of TLR9 agonists for cancer therapy. J Clin Invest 2007;117(5):1184-94. [PubMed: 17476348]

18. Yang JM, Hildebrandt B, Luderschmidt C, Pollard KM. Human scleroderma sera contain autoantibodies to protein components specific to the U3 small nucleolar RNP complex. Arthritis Rheum 2003;48(1):210-7. [PubMed: 12528121]

19. Fatica A, Galardi S, Altieri F, Bozzoni I. Fibrillarin binds directly and specifically to U16 box C/D snoRNA. Rna 2000;6(1):88-95. [PubMed: 10668801]

20. Baserga SJ, Yang XD, Steitz JA. An intact Box C sequence in the U3 snRNA is required for binding of fibrillarin, the protein common to the major family of nucleolar snRNPs. Embo J 1991;10(9): 2645-51. [PubMed: 1714385]

21. Hornung V, Barchet W, Schlee M, Hartmann G. RNA recognition via TLR7 and TLR8. Handb Exp Pharmacol 2008;(183):71-86. [PubMed: 18071655] 
22. Pisitkun P, Deane JA, Difilippantonio MJ, Tarasenko T, Satterthwaite AB, Bolland S. Autoreactive B cell responses to RNA-related antigens due to TLR7 gene duplication. Science 2006;312(5780): 1669-72. [PubMed: 16709748]

**23. Seki E, De Minicis S, Osterreicher CH, Kluwe J, Osawa Y, Brenner DA, et al. TLR4 enhances TGF-beta signaling and hepatic fibrosis. Nat Med 2007;13(11):1324-32. [PubMed: 17952090]

**24. Sugiura H, Ichikawa T, Koarai A, Yanagisawa S, Minakata Y, Matsunaga K, et al. Activation of Toll-like receptor 3 augments myofibroblast differentiation. Am J Respir Cell Mol Biol 2009;40 (6):654-62. [PubMed: 18988918]

*25. Meneghin A, Choi ES, Evanoff HL, Kunkel SL, Martinez FJ, Flaherty KR, et al. TLR9 is expressed in idiopathic interstitial pneumonia and its activation promotes in vitro myofibroblast differentiation. Histochem Cell Biol 2008;130(5):979-92. [PubMed: 18633634]

*26. Fineschi S, Goffin L, Rezzonico R, Cozzi F, Dayer JM, Meroni PL, et al. Antifibroblast antibodies in systemic sclerosis induce fibroblasts to produce profibrotic chemokines, with partial exploitation of toll-like receptor 4. Arthritis Rheum 2008;58(12):3913-23. [PubMed: 19035500]

27. Jiang D, Liang J, Fan J, Yu S, Chen S, Luo Y, et al. Regulation of lung injury and repair by Toll-like receptors and hyaluronan. Nat Med 2005;11(11):1173-9. [PubMed: 16244651]

28. Schaefer L, Babelova A, Kiss E, Hausser HJ, Baliova M, Krzyzankova M, et al. The matrix component biglycan is proinflammatory and signals through Toll-like receptors 4 and 2 in macrophages. J Clin Invest 2005;115(8):2223-33. [PubMed: 16025156]

29. Gavin AL, Hoebe K, Duong B, Ota T, Martin C, Beutler B, et al. Adjuvant-enhanced antibody responses in the absence of toll-like receptor signaling. Science 2006;314(5807):1936-8. [PubMed: 17185603]

30. Kanneganti TD, Lamkanfi M, Nunez G. Intracellular NOD-like receptors in host defense and disease. Immunity 2007;27(4):549-59. [PubMed: 17967410]

31. Gitlin L, Barchet W, Gilfillan S, Cella M, Beutler B, Flavell RA, et al. Essential role of mda-5 in type I IFN responses to polyriboinosinic:polyribocytidylic acid and encephalomyocarditis picornavirus. Proc Natl Acad Sci U S A 2006;103(22):8459-64. [PubMed: 16714379]

*32. Hausmann S, Marq JB, Tapparel C, Kolakofsky D, Garcin D. RIG-I and dsRNA-induced IFNbeta activation. PLoS ONE 2008;3(12):e3965. [PubMed: 19115016]

33. Hornung V, Ablasser A, Charrel-Dennis M, Bauernfeind F, Horvath G, Caffrey DR, et al. AIM2 recognizes cytosolic dsDNA and forms a caspase-1-activating inflammasome with ASC. Nature 2009;458(7237):514-8. [PubMed: 19158675]

34. Cohen RA, Patel A, Green FH. Lung disease caused by exposure to coal mine and silica dust. Semin Respir Crit Care Med 2008;29(6):651-61. [PubMed: 19221963]

35. Rustin MH, Bull HA, Ziegler V, Mehlhorn J, Haustein UF, Maddison PJ, et al. Silica-associated systemic sclerosis is clinically, serologically and immunologically indistinguishable from idiopathic systemic sclerosis. Br J Dermatol 1990;123(6):725-34. [PubMed: 2176091]

**36. Cassel SL, Eisenbarth SC, Iyer SS, Sadler JJ, Colegio OR, Tephly LA, et al. The Nalp3 inflammasome is essential for the development of silicosis. Proc Natl Acad Sci U S A 2008;105 (26):9035-40. [PubMed: 18577586]

**37. Hornung V, Bauernfeind F, Halle A, Samstad EO, Kono H, Rock KL, et al. Silica crystals and aluminum salts activate the NALP3 inflammasome through phagosomal destabilization. Nat Immunol 2008;9(8):847-56. [PubMed: 18604214]

**38. Gasse P, Mary C, Guenon I, Noulin N, Charron S, Schnyder-Candrian S, et al. IL-1R1/MyD88 signaling and the inflammasome are essential in pulmonary inflammation and fibrosis in mice. $\mathrm{J}$ Clin Invest 2007;117(12):3786-99. [PubMed: 17992263]

39. Ogura Y, Sutterwala FS, Flavell RA. The inflammasome: first line of the immune response to cell stress. Cell 2006;126(4):659-62. [PubMed: 16923387]

40. Bonniaud P, Margetts PJ, Ask K, Flanders K, Gauldie J, Kolb M. TGF-beta and Smad3 signaling link inflammation to chronic fibrogenesis. J Immunol 2005;175(8):5390-5. [PubMed: 16210645]

*41. Yang HZ, Cui B, Liu HZ, Chen ZR, Yan HM, Hua F, et al. Targeting TLR2 attenuates pulmonary inflammation and fibrosis by reversion of suppressive immune microenvironment. J Immunol 2009;182(1):692-702. [PubMed: 19109203] 
42. Hill RH Jr. Schurz HH, Posada de la Paz M, Abaitua Borda I, Philen RM, Kilbourne EM, et al. Possible etiologic agents for toxic oil syndrome: fatty acid esters of 3-(N-phenylamino)-1,2-propanediol. Arch Environ Contam Toxicol 1995;28(2):259-64. [PubMed: 7710294]

43. Posada de la Paz M, Philen RM, Schurz H, Hill RH Jr. Gimenez Ribota O, Gomez de la Camara A, et al. Epidemiologic evidence for a new class of compounds associated with toxic oil syndrome. Epidemiology 1999;10(2):130-4. [PubMed: 10069247]

44. Bell SA, Page S, Baumgartner B, Berking C, Haas M, Eisele T, et al. Involvement of nuclear factorkappaB in a murine model for the acute form of autoimmune-like toxic oil syndrome. Toxicol Appl Pharmacol 1999;157(3):213-21. [PubMed: 10373405]

45. Cai P, Khan MF, Kaphalia BS, Ansari GA. Immunotoxic Response of Oleic Acid Anilide and its Hydrolysis Products in Female MRL (+/+) Mice. J Immunotoxicol 2005;2(4):231-6. [PubMed: 18958679]

46. Bomford R. The adjuvant activity of fatty acid esters. The role of acyl chain length and degree of saturation. Immunology 1981;44(1):187-92. [PubMed: 7275184]

*47. Wermuth PJ, Del Galdo F, Jimenez SA. Induction of the expression of profibrotic cytokines and growth factors in normal human peripheral blood monocytes by gadolinium contrast agents. Arthritis Rheum 2009;60(5):1508-18. [PubMed: 19404939]

48. Tousova K, Vyklicky L, Susankova K, Benedikt J, Vlachova V. Gadolinium activates and sensitizes the vanilloid receptor TRPV1 through the external protonation sites. Mol Cell Neurosci 2005;30(2): 207-17. [PubMed: 16099171]

49. Fisher ER, Rodnan GP. Pathologic observations concerning the cutaneous lesion of progressive systemic sclerosis: an electron microscopic histochemical and immunohistochemical study. Arthritis Rheum 1960;3:536-545. [PubMed: 13699954]

50. Del Galdo F, Maul GG, Jimenez SA, Artlett CM. Expression of allograft inflammatory factor 1 in tissues from patients with systemic sclerosis and in vitro differential expression of its isoforms in response to transforming growth factor beta. Arthritis Rheum 2006;54(8):2616-25. [PubMed: 16868985]

51. Duan H, Fleming J, Pritchard DK, Amon LM, Xue J, Arnett HA, et al. Combined analysis of monocyte and lymphocyte messenger RNA expression with serum protein profiles in patients with scleroderma. Arthritis Rheum 2008;58(5):1465-74. [PubMed: 18438864]

52. Munder M, Eichmann K, Modolell M. Alternative metabolic states in murine macrophages reflected by the nitric oxide synthase/arginase balance: competitive regulation by CD4+ T cells correlates with Th1/Th2 phenotype. J Immunol 1998;160(11):5347-54. [PubMed: 9605134]

53. Aliprantis AO, Wang J, Fathman JW, Lemaire R, Dorfman DM, Lafyatis R, et al. Transcription factor T-bet regulates skin sclerosis through its function in innate immunity and via IL-13. Proc Natl Acad Sci U S A 2007;104(8):2827-30. [PubMed: 17307869]

54. Lakos G, Melichian D, Wu M, Varga J. Increased bleomycin-induced skin fibrosis in mice lacking the Th1-specific transcription factor T-bet. Pathobiology 2006;73(5):224-37. [PubMed: 17314493]

55. Yamamoto T, Nishioka K. Animal model of sclerotic skin. VI: Evaluation of bleomycin-induced skin sclerosis in nude mice. Arch Dermatol Res 2004;295(10):453-6. [PubMed: 14673598]

56. Helene M, Lake-Bullock V, Zhu J, Hao H, Cohen DA, Kaplan AM. T cell independence of bleomycininduced pulmonary fibrosis. J Leukoc Biol 1999;65(2):187-95. [PubMed: 10088601]

57. Hancock A, Armstrong L, Gama R, Millar A. Production of interleukin 13 by alveolar macrophages from normal and fibrotic lung. Am J Respir Cell Mol Biol 1998;18(1):60-5. [PubMed: 9448046]

58. Hasegawa M, Fujimoto M, Kikuchi K, Takehara K. Elevated serum levels of interleukin 4 (IL-4), IL-10, and IL-13 in patients with systemic sclerosis. J Rheumatol 1997;24(2):328-32. [PubMed: 9034992] 